\title{
BMJ Open Association of age-related macular degeneration on fracture risks among osteoporosis population: a nationwide population-based cohort study
}

\author{
Chi Chin Sun (D) , ${ }^{1,2,3}$ Ting-Shuo Huang, ${ }^{4}$ Tsai-Sheng Fu, ${ }^{5}$ Chia-Yi Lee, ${ }^{6}$ \\ Bing-Yu Chen, ${ }^{3}$ Fang-Ping Chen ${ }^{7}$
}

To cite: Sun CC, Huang T-S, Fu T-S, et al. Association of age-related macular degeneration on fracture risks among osteoporosis population: a nationwide populationbased cohort study. BMJ Open 2020;10:e037028. doi:10.1136/ bmjopen-2020-037028

- Prepublication history for this paper is available online. To view these files, please visit the journal online (http://dx.doi org/10.1136/bmjopen-2020037028).

Received 17 January 2020 Revised 10 July 2020 Accepted 23 July 2020
Check for updates

(C) Author(s) (or their employer(s)) 2020. Re-use permitted under CC BY-NC. No commercial re-use. See rights and permissions. Published by BMJ.

For numbered affiliations see end of article.

Correspondence to Dr Fang-Ping Chen; fangping@cgmh.org.tw

\section{ABSTRACT}

Objectives Visual impairment is an important risk factor for fracture in the elderly population. Age-related macular degeneration (AMD) is the leading cause of irreversible visual impairment in elderly people. This study was conducted to explore the relationship between AMD and incident fractures in patients with osteoporosis (OS).

Design Retrospective analysis of Taiwan's National Health Insurance Research Database (NHIRD).

Setting A multicenter study conducted in Taiwan.

Participants and controls The current study used the NHIRD in Taiwan between 1996 and 2011. A total of 13 584 and 54336 patients with OS were enrolled in the AMD group and the non-AMD group, respectively.

Intervention Patients with OS were included from the Taiwan's NHIRD after exclusion, and each patient with AMD was matched for age, sex and comorbidities to four patients with non-AMD OS, who served as the control group. A Cox proportional hazard model was used for the multivariable analysis.

Primary outcome measures Transitions for OS to spine fracture, OS to hip fracture, OS to humero-radio-ulnar fracture and OS to death.

Results The risks of spine and hip fractures were significantly higher in the AMD group $(\mathrm{HR}=1.09,95 \%$ $\mathrm{Cl}=1.04$ to $1.15, \mathrm{p}<0.001 ; \mathrm{HR}=1.18 ; 95 \% \mathrm{Cl}=1.08$ to $1.30, p=0.001$, respectively) than in the non-AMD group. The incidence of humero-radio-ulnar fracture between AMD and non-AMD individuals was similar ( $\mathrm{HR}=0.98$; $95 \%$ $\mathrm{Cl}=0.90$ to $1.06 ; \mathrm{p}=0.599$ ). However, the risk of death was higher in patients with OS with older age, male sex and all types of comorbidity $(p<0.05)$, except for hyperthyroidism $(p=0.200)$.

Conclusion Patients with OS with AMD had a greater risk of spine and hip fractures than did patients without AMD.

\section{INTRODUCTION}

Poor vision is common in the elderly population. Ocular diseases such as cataract, glaucoma and age-related macular degeneration (AMD) are strongly age-related, ${ }^{1-4}$ and there is accumulating evidence demonstrating that many elderly people would benefit from changing eyeglasses. ${ }^{25}$ AMD is one of the
Strengths and limitations of this study

- The current study enrolled a large number of participants 13548 (age-related macular degeneration (AMD) group) patients and 54336 (a non-AMD group) patients.

- Each participant can be followed up to 16 years even when visited to different hospitals.

- The causal relationship between AMD and subsequent bone fracture in patients with osteoporosis (OS) has not yet been established in the current study.

- The disease severity of OS is inaccessible in the Taiwan's National Health Insurance Research Database because of simply using the International Classification of Diseases, Ninth Revision, Clinical Modification diagnostic codes.

- The severity of ocular disease leading to fractures or higher mortality rate has not yet been determined.

leading causes of irreversible visual impairment in elderly people in developed countries. $^{6-8}$ The estimated incidence of AMD in Taiwan is approximately $10.8 \% .^{9}$ Although, it does not result in complete blindness; however, the loss of central vision can make it difficult to perform daily activities such as recognising faces, driving and reading. ${ }^{10}$ According to a previous report, patients with AMD are in greater fear of falling down, which can restrict their social activities. ${ }^{11}$ Moreover, individuals with AMD have a higher probability to fall with more unsteady gait patterns. ${ }^{12} 13$

Osteoporosis (OS) is a chronic metabolic bone disease in which bones become relatively weak and have a probability to break. ${ }^{14}$ The prevalence of OS is estimated to be $11.35 \%$ among women over 50 years old. ${ }^{15}$ It has been observed that patients with OS tend to develop fractures of the hip, vertebrae, distal forearm and humerus, ${ }^{16}$ and fractures among elderly patients represent 
an important public health issue. ${ }^{17}$ Taiwan's population is ageing at an alarming rate ${ }^{15}$; OS and related fractures pose an unprecedented threat to the elderly population in Taiwan since the prevalence of OS increases rapidly with age. ${ }^{14}$ As fractures in the elderly would contribute to a higher probability of mortality despite promptly surgical intervention, ${ }^{18} 19$ potential risk factors for individuals vulnerable to fractures, such as those with OS, should be further investigated and identified.

Visual impairment is an important risk factor for hip fracture in the elderly population. ${ }^{20-22}$ Studies have revealed that macular degeneration and glaucoma suspect would lead to a higher risk of hip fractures. ${ }^{22}$ Therefore, it is important to understand the ocular risk factors and take measures to prevent future fractures in patients with OS. However, only a limited number of studies have examined the association between fractures in patients with OS and specific ocular disorders. ${ }^{22-24}$ Taking AMD as an example, studies focused only on patients with AMD and hip fractures, ignoring spine and humero-radio-ulnar fractures. ${ }^{22-24}$ Moreover, the number of participants in previous studies was relatively small, ${ }^{22-24}$ while a population-based study should be conducted to investigate the relationship between AMD and fractures in patients with OS since both disorders affect most population. ${ }^{14}$

Therefore, we used the Taiwan's National Health Insurance Research Database (NHIRD) in this nationwide study with a retrospective cohort and a case-control design to investigate the association between AMD and subsequent fractures in patients with OS.

\section{METHODS}

\section{Ethics declaration and patient involvement statement}

Participants in this study were adhered to the 1964 Declaration of Helsinki and its later amendments.

\section{Patient and public involvement statement}

As this is a claimed data-based study, data were collected and produced by the National Health Insurance (NHI) Administration of Taiwan without patient recruitment; the requirement for informed consent was waived by both the NHI Administration and the Institutional Review Board of Chang Gung Memorial Hospital.

\section{Data source}

This population-based cohort study used the NHIRD of Taiwan (approximately 26 million insured individuals) for the period January 1996 to December 2011. By the end of 2007, NHIRD had enrolled more than $99 \%$ of Taiwan's population into this insurance programme, which had contracts with $97 \%$ of the country's clinics and hospitals. The data available through the NHIRD included all medical services provided to each enrollee from 1 January 1996 to 31 December 2011, as well as the patients' characteristics and the features of the hospitals and physicians.

\section{Study population enrolment and exclusion criteria}

We identified patients with diagnosis of OS using the International Classification of Diseases, Ninth Revision, Clinical Modification (ICD-9) codes 733.00, 733.01, 733.02, 733.03 and 733.09. The osteoporotic population of the NHIRD was identified by the presence of either the abovementioned diagnostic codes in their outpatient records or the discharge codes from hospitalisation records. Eligible patients were those 50 years of age or older with diagnosis of OS. Exclusion criteria were as follows: (1) received osteoporotic medical treatments for more than 30 days before the index date; (2) any fractures documented before the index date (ICD-9 codes 800.x-829.x); (3) having a diagnosis of HIV (ICD-9 codes 042) and (4) being diagnosed with metastatic solid tumours (ICD-9 codes 196.x-198.x). Furthermore, we divided patients into those with AMD (AMD group with primary diagnosis codes of ICD-9 362.50-362.52) and those without AMD (non-AMD group). After propensity score matching, 13 548 patients and 54336 patients were analysed in the AMD and non-AMD group, respectively.

\section{Outcome definition}

We identified hospitalised patients who were admitted with a primary diagnosis of hip fracture (ICD-9 codes 820.x), spine fracture (ICD-9 codes 806 .x) and humeroradio-ulnar fractures (ICD-9 codes 812.x and 813.x) for the first time after 2002 (ensuring no previous hip, spine and humero-radio-ulnar fractures between 1996 and 2001) and who received surgery for fractures to make sure the diagnostic accuracy (surgery code of NHIRD: 64245C, 64042C, 64160B, 64271B, 64271C, 64032B). The date of death was defined as the expired date recorded in the catastrophic illness registry data files, the discharge date from a patient's insurance coverage within 1 month after being critical against medical advice discharge or the discharge date from a patient's insurance coverage within 1 month after emergency department discharge with intravenous epinephrine use. We defined it as such because the NHI is mandatory in Taiwan; therefore, patients, especially sick ones, can rarely stop their own insurance coverage. If the insurance coverage ended, death was the reason. Furthermore, NHI premiums are paid monthly, so coverage can be stopped immediately following a death. The time-to-event outcome was determined as the time from the OS diagnosis date to the date of hip fracture, spine fracture and humero-radio-ulnar fractures, or all-cause death, respectively.

\section{Covariates}

The comorbidities were defined as an outpatient diagnosis listed on two or more visits or a one-time inpatient diagnosis before the index date. Study comorbidities included diabetes mellitus (DM), moderate to severe liver disease, chronic renal disease, hyperthyroidism, rheumatic disease, malignancy, hyperparathyroidism and ocular diseases including cataract, corneal diseases and glaucoma. The Charlson Comorbidity Index score 
Patients with a diagnosis of osteoporosis between 1996 and 2011 ( $n=1850205$ )

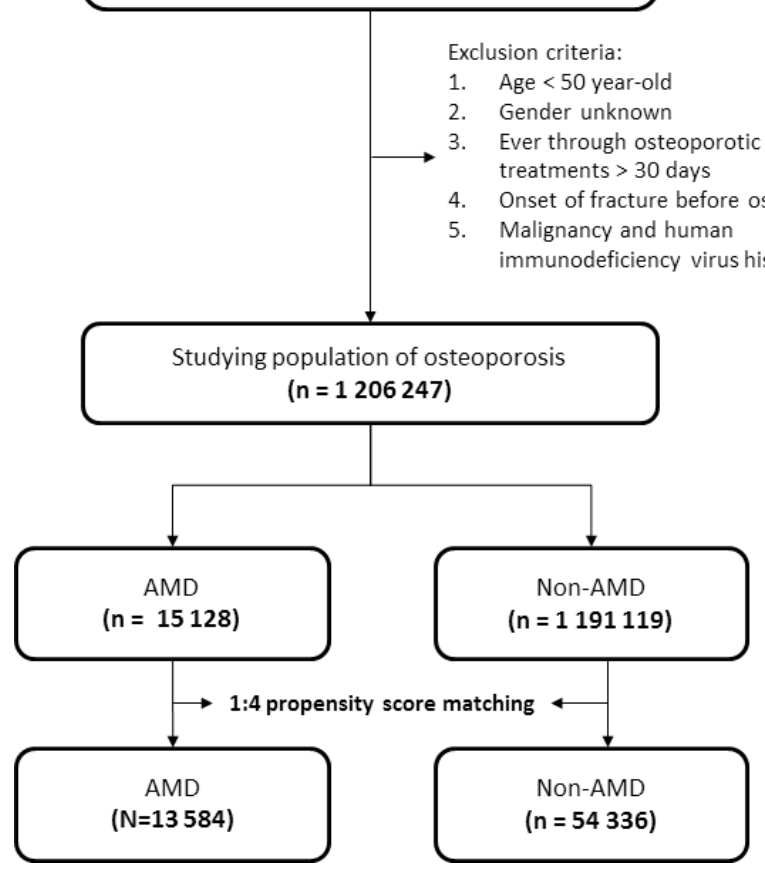

Figure 1 Flowchart of the patient selection in AMD and non-AMD cohort with a one-to-four match. AMD, age-related macular degeneration.

(CCIs) that merges the abovementioned diseases into one numerical score was also recorded.

\section{Statistical analysis}

To compare the AMD and each transition, we performed propensity score matching. The propensity score was the predicted probability of being the AMD group given the values of covariates including age, sex, rheumatologic diseases, DM with and without complications, malignancy, moderate to severe liver diseases, hyperthyroidism, chronic renal diseases, cataract, corneal disease, glaucoma, hyperparathyroidism and CCIs. Each patient in the AMD group was matched with four counterparts in the non-AMD group to achieve minimal bias. The cumulative incidence of follow-up outcomes was generated and the comparisons between the two groups for the risk of spine, hip and humero-radio-ulnar fractures were made using the Cox proportional hazards model in which death was considered a competing risk. We checked the proportional hazards assumption using modified Schoenfeld residuals test and residual plots in each Cox model. For the violation of proportional hazards assumption, we demonstrated the interaction between the variable and time using step functions or functions guided from residual plots. To investigate the cumulative incidence of each fracture and cause of death, we engaged in the competing risk model with the HR adjusted all the above mentioned covariates to analyse the transitions, including 'OS to spine fracture', 'OS to hip fracture', 'OS to humero-radio-ulnar fracture' between AMD and non-AMD subjects, and the transition of 'OS to death' for the abovementioned covariates. Finally, to facilitate the interpretation of time-varying coefficients, we conducted postestimation simulation techniques and graphs with visual weight to demonstrate the results. All reported CIs and tests were two-sided with a $5 \%$ significance level. All analyses were performed with R V.3.3.0 (R Foundation for Statistical Computing, Vienna, Austria) with contributed packages 'tableone', 'ReporteRs', 'mstate', 'survival', 'ggplot2' and 'simPH'.

\section{RESULTS}

\section{Patient characteristics}

A total of 1850205 patients with OS were enrolled in this nationwide study. After applying the exclusion criteria, a total of 1206247 patients participated, of which 15128 were in the AMD group and 18191119 were in the nonAMD group. After propensity score matching, 13548 patients and 54336 patients were analysed in the AMD and non-AMD group, respectively (figure 1). The selected characteristics-including age, sex, related covariates and CCIs-were well balanced between the AMD and nonAMD groups after propensity score matching (table 1).

\section{Estimates of cumulative hazards and probabilities of transition}

During the follow-up period in the study population, $8930(13.1 \%)$ patients with OS had spine fractures, $2461(3.6 \%)$ hip fractures, humero-radio-ulnar fractures occurred in $3470(5.1 \%)$ patients with OS and $8123(13.0 \%)$ patients with OS unfortunately died. During the follow-up period, the entire study population had higher risks for spine fracture and death compared with humero-radio-ulnar fracture and hip fracture (figure 2).

\section{The effect of AMD on transition of fractures}

In the multivariate analysis, a patient with OS with AMD was significantly associated with a high risk of spine fracture after adjusting for covariates $(\mathrm{HR}=1.09 ; 95 \% \mathrm{CI}=1.04$ to 1.15 ; $\mathrm{p}<0.001)$ compared with a non-AMD individual. Similarly, AMD was significantly associated with a high risk of hip fracture $(\mathrm{HR}=1.18 ; 95 \% \mathrm{CI}=1.08$ to $1.30 ; \mathrm{p}<0.001)$ than a patient without AMD. However, AMD was not associated with risks for the humero-radio-ulnar fracture $(\mathrm{HR}=0.98 ; 95 \% \mathrm{CI}=0.90$ to $1.06 ; \mathrm{p}=0.599)$. Additionally, multivariate analysis also revealed that older age, male sex and all non-ocular medical comorbidities, except for hyperthyroidism $(\mathrm{p}=0.200)$, were significantly associated with higher risks for death $(p<0.05)$ (table 2). The fact that with increasing age and being female are vulnerable to any type of incident fractures is also shown in our results (table 2). It is also noteworthy that other ocular comorbidities, including cataract and corneal diseases, are associated with a high risk of spine fractures ( $\mathrm{HR}=1.23 ; 95 \%$ $\mathrm{CI}=1.17$ to $1.31 ; \mathrm{p}<0.001$ and $\mathrm{HR}=1.18 ; 95 \% \mathrm{CI}=1.12$ to 1.23 ; $\mathrm{p}<0.001)$ and humero-radio-ulnar fractures $(\mathrm{HR}=1.16 ; 95 \%$ $\mathrm{CI}=1.06$ to $1.26 ; \mathrm{p}<0.001$ and $\mathrm{HR}=1.08 ; 95 \% \mathrm{CI}=1.00$ to 1.17 ; $\mathrm{p}=0.041$ ). However, a patient with OS with glaucoma is not associated with a high risk of any incident fractures, which 
Table 1 Baseline characteristics between the AMD and non-AMD groups

\begin{tabular}{|c|c|c|c|}
\hline & AMD $(n=13584)$ & Non-AMD $(n=54336)$ & $P$ value \\
\hline Age, median (IQR) & $73.8(67.2-79.3)$ & $73.8(67.2-79.3)$ & 1 \\
\hline \multicolumn{4}{|l|}{ Age group, No (\%) } \\
\hline$\geq 50$ to $<60$ & $1277(9.4)$ & $5075(9.3)$ & 0.98 \\
\hline$\geq 60$ to $<70$ & $3372(24.8)$ & $13424(24.7)$ & \\
\hline$\geq 70$ to $<80$ & $5881(43.3)$ & $23603(43.4)$ & \\
\hline 80 & 3054 (22.5) & $12234(22.5)$ & \\
\hline \multicolumn{4}{|l|}{ Sex, No (\%) } \\
\hline Female & $8081(59.5)$ & 32324 (59.5) & 1 \\
\hline Rheumatologic diseases, No (\%) & $846(6.2)$ & $3384(6.2)$ & 1 \\
\hline DM without complications, No (\%) & 4101 (30.2) & $16404(30.2)$ & 1 \\
\hline DM with complications, No (\%) & $1629(12.0)$ & $6516(12.0)$ & 1 \\
\hline Malignancy, No (\%) & $1470(10.8)$ & $5880(10.8)$ & 1 \\
\hline Moderate to severe liver diseases, No (\%) & $19(0.1)$ & $76(0.1)$ & 1 \\
\hline Hyperthyroidism, No (\%) & $204(1.5)$ & $816(1.5)$ & 1 \\
\hline Chronic renal diseases, No (\%) & $598(4.4)$ & $2392(4.4)$ & 1 \\
\hline Cataract, No (\%) & $10276(75.6)$ & $41104(75.6)$ & 1 \\
\hline Corneal disease, No (\%) & 2665 (19.6) & $10660(19.6)$ & 1 \\
\hline Glaucoma, No (\%) & 2037 (15.0) & $8148(15.0)$ & 1 \\
\hline CCls, median (IQR) & $5.00(3.00-7.00)$ & $5.00(3.00-7.00)$ & 0.22 \\
\hline
\end{tabular}

AMD, age-related macular degeneration; CCls, Charlson Comorbidity Index score; DM, diabetes mellitus; No, number of patients.

is due to the relatively fewer cases and the heterogeneous disease stages in this study cohort.

\section{DISCUSSION}

In this study, our results showed that AMD incurred a 1.09-fold and 1.18-fold risk of subsequent spine hip fractures, respectively, in patients with OS older than 50 years after adjusting for demography, ocular and systemic

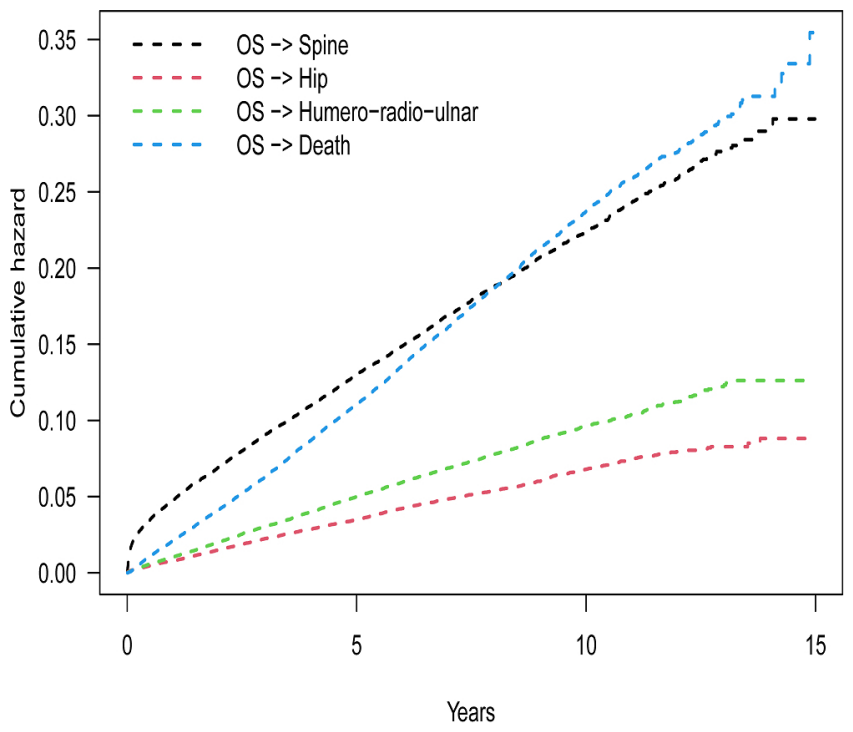

Figure 2 Estimates of cumulative hazards of transition among patients with OS. OS, osteoporosis. comorbidities. However, AMD did not increase the risk of humero-radio-ulnar fracture in this multivariate model.

About a third of the elderly population living in the community suffered from one or more falls each year, ${ }^{25}$ which can damage one that has OS easily and lead to severe injury, physical deterioration, institutionalisation and incident deaths. ${ }^{26}$ Most falls resulted from the interactions of multiple risk factors, including age, muscle weakness, poor vision, difficulties with gait and balance, previous falls, fear of falling and chronic illnesses such as arthritis, DM, stroke, Parkinson's disease, incontinence and dementia. ${ }^{2528}$ It is well recognised that fall-related ocular risk factors are also major contributors to fractures in the elderly, ${ }^{22}$ which was supported by the findings of the current study.

Many older people living in the community were affected by poor vision or eye disease such as cataract, glaucoma and macular degeneration. ${ }^{129}$ Studies have also demonstrated that AMD is associated with an increased risk of hip fractures by analysing the medicare database. ${ }^{232430}$ Anastasopoulos $e t a \hat{l}^{0}$ found that the risk of hip fractures was significantly higher in cases that were coded with atrophic (dry) AMD.$^{30}$ However, the risk was similar in cases that were coded with exudative AMD and cases with no AMD. This study revealed that patients with a code for both types of AMD had significantly greater risk of hip fractures than patients without a code for AMD in osteoporotic population. The higher risk in this study reflected the fact that patients with OS are a potentially 


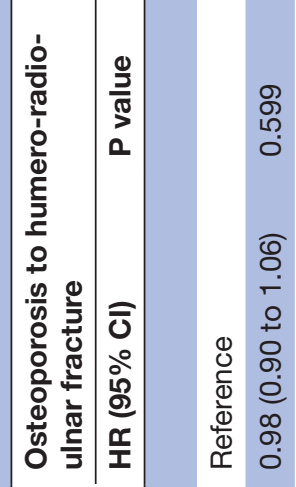

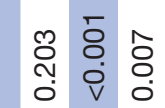

$\overline{8}$
จ
v

용

옹

กิ

$\bar{\infty}$
10
0

สูฐ

ô
+̊.
0
0
0
0

๑ \&

ฮั

产

อ

ชั

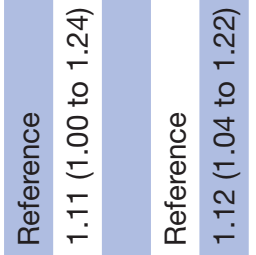

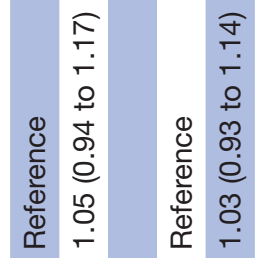

$\begin{array}{ll}\overline{8} & 0 \\ 0 & 0 \\ 0 & 0\end{array}$

ণ্ণী

$\overline{8}$
$\dot{0}$
v

0
8
0

ส

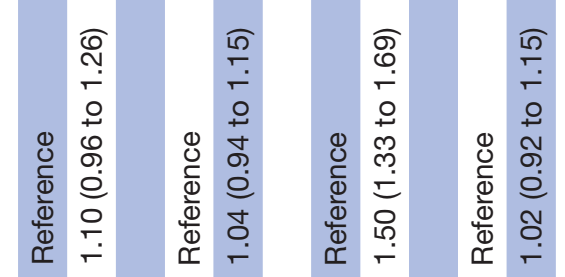

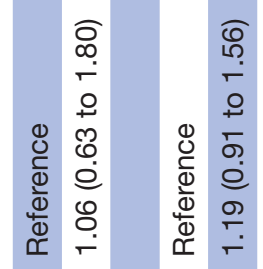

䇋

$\overline{8}$
Q
v

के

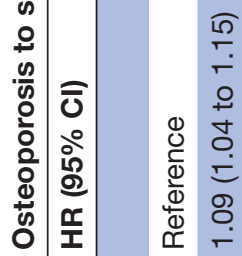

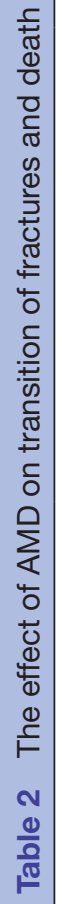

$\bar{\delta}$
$\overline{0}$
$\dot{0}$
$\dot{0}$
v

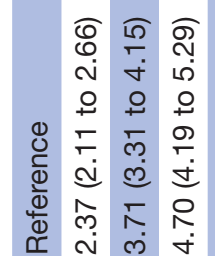

$\begin{array}{lll}\overline{8} & \overline{8} & \overline{8} \\ \dot{0} & 0 & 0 \\ \text { v } & \end{array}$

ชิ สํㅇㅇ

당ำ

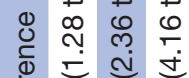

竞

离 $\overline{8}$
0
0

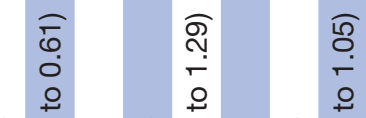

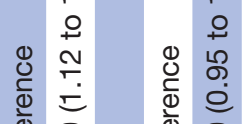

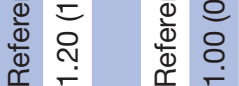

$\overline{8}$
ํ

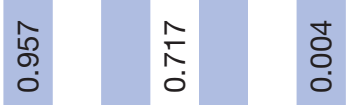

$\wedge$
$\infty$
0

ญ़ָ

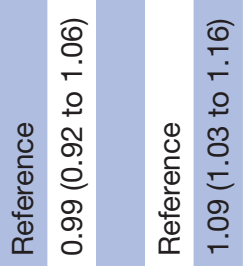

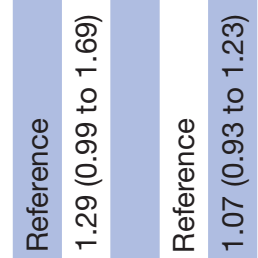

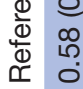

$\bar{\delta}$
$\circ$
$\dot{0}$

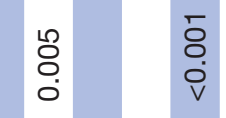

$\begin{array}{ll}\overline{0} & \bar{\delta} \\ \circ & 0 \\ \dot{0} & \dot{v}\end{array}$

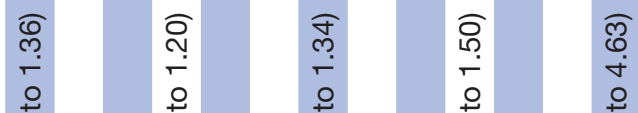

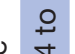

密

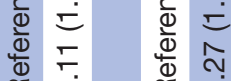

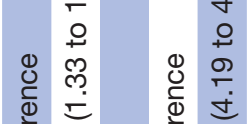

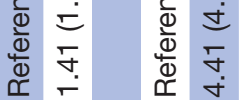

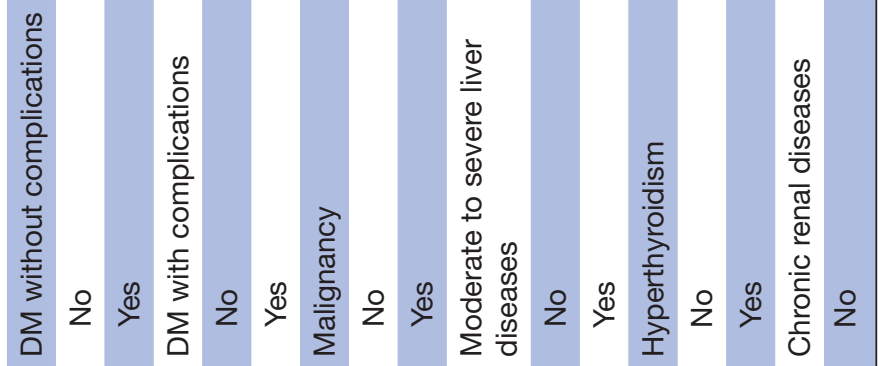

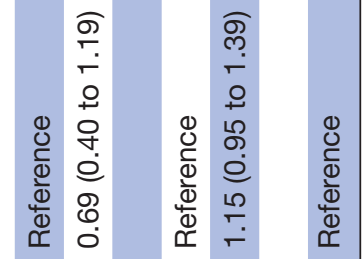

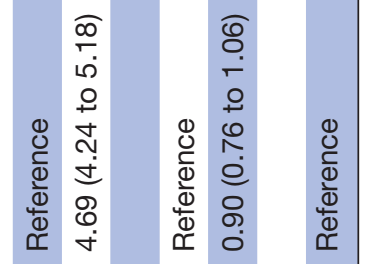

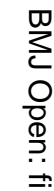

$\stackrel{\overrightarrow{0}}{\stackrel{9}{0}}$

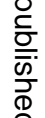

@)

$\overrightarrow{0}$
$\stackrel{\vec{\omega}}{\mathrm{\omega}}$
Oे
$\frac{\mathrm{O}}{3}$
$\frac{\mathrm{O}}{\mathrm{O}}$

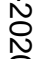

产

$\infty$

品

$\vec{v}$

$\underset{\mathbb{D}}{\stackrel{D}{\Phi}}$

总

N

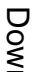

วิ

$\stackrel{\bar{D}}{2}$

혹

吾

홍.

$\dot{0}$

ㅇํํ

운

을.

N

Nิ

ত

잉

뭉

옹

항

হ

흘 


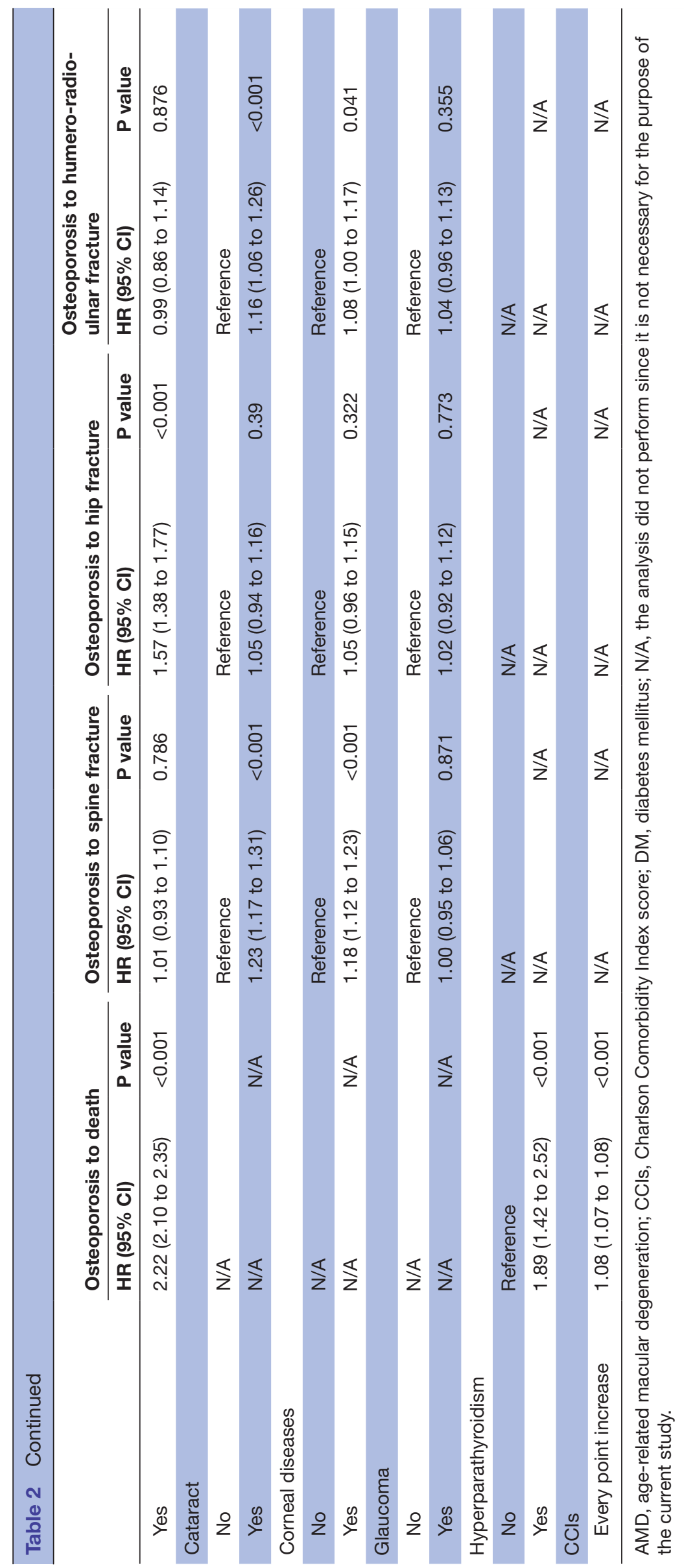

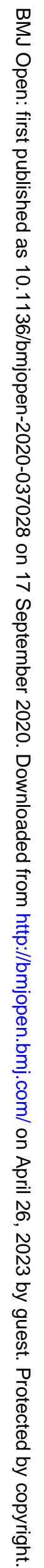


vulnerable population to developing fractures secondary to an accidental fall.

Fractures caused by OS most frequently occur in the spine. ${ }^{14}$ These spinal fractures occur in nearly 700000 patients each year in the USA and is twice as common as other OS-related fractures such as hip and wrist fractures. ${ }^{31}$ Generally, spinal compression fractures result from falls, ${ }^{32}$ but patients with OS can suffer fractures even when doing routine works, such as twisting, coughing and sneezing. ${ }^{33}$ However, there are very few reports on the association between AMD and spine fractures in patients with OS. In this study, patients with AMD have a significantly greater risk of spine fractures. Therefore, it is important to screen ocular comorbidity such as AMD in elderly patients with OS to prevent both hip and spine fractures.

This study demonstrated that AMD was not associated with a greater risk of humero-radio-ulnar fractures. Primarily because humerus fractures occur in a relatively young population after physical trauma, falls, excess physical stress such as baseball games ${ }^{34}$ and even with the presence of AMD, it did not cause significant visual impairment at a relatively younger age. However, proximal humerus fractures occur among elderly patients with OS who fall on an outstretched arm, ${ }^{35}$ which corresponded to our finding in which 70 years or older were associated with an increased risk of humeroradio-ulnar fractures (table 2).

The risk of death was significantly higher in patients with OS with older age, male sex and the majority of systemic diseases in the current study. It is reasonable since the factors are related to a relatively unhealthy status; however, the nonsignificant relationship between hyperparathyroidism and death in OS individuals needs further validation. Although the chance of death is increased in patients with OS with systemic comorbidities, attention should be paid to the fact that these patients with additional AMD diagnosis have a higher risk of spine and hip fractures and subsequent death caused by fractures. ${ }^{18} 19$ Therefore, we should aggressively treat AMD to prevent fractures in patients with OS if they are not affected by severe systemic diseases.

A major limitation of this study is that the disease severity is inaccessible in the NHIRD and the effects of different severities of ocular comorbidities on different fractures cannot be obtained. However, it seemed unlikely that selection bias was a factor given that the basis of subject selection was not associated with the magnitude of fractures and the severity of ocular comorbidities. A minor limitation lies in the absence of outcome measures after treatment for both AMD and OS, which cannot provide therapeutic guidelines.

In conclusion, patients with OS with AMD are at a significantly higher risk of subsequent development of spine and hip fractures, but not humero-radio-ulnar fractures than matched controls. Moreover, older age, male sex and major systemic comorbidities in patients with OS are related to death. Further investigations are needed to clarify if the treatment of AMD, such as vitrectomy and intravitreal antivascular endothelial growth factor injection, would prevent primary fractures in patients with OS.
Author affiliations

${ }^{1}$ Department of Ophthalmology, Chang Gung Memorial Hospital, Keelung, Taiwan ${ }^{2}$ School of Medicine, College of Medicine, Chang Gung University, Taoyuan, Taiwan ${ }^{3}$ Department of Medical Research and Development, Chang Gung Memorial Hospital, Keelung, Taiwan

${ }^{4}$ Department of General Surgery, Chang Gung Memorial Hospital, Keelung, Taiwan ${ }^{5}$ Department of Orthopedic Surgery, Chang Gung Memorial Hospital, Keelung, Taiwan

${ }^{6}$ Department of Ophthalmology, Show Chwan Memorial Hospital, Changhua, Taiwan ${ }^{7}$ Department of Obstetrics and Gynecology, Chang Gung Memorial Hospital, Keelung, Taiwan

Acknowledgements We extend our deepest gratitude to Biostatistics Consultation Centre at Chang Gung Memorial Hospital, Keelung, Taiwan, for offering us informative suggestions along the way regarding statistical analysis.

Contributors T-SH, F-PC and CCS contributed to the concept and design of the study; CCS-and B-YC contributed to analyses of data. CCS, T-SF and B-YC contributed to interpretation of the data; C-YL, F-PC and CCS contributed to manuscript writing. F-PC had full access to all the data in the study and takes responsibility for the integrity of the data and the accuracy of the data analysis. All authors included CCS, T-SH, T-SF, C-YL, B-YC and F-PC contributed to the critical revision of the study and the approval of submission.

Funding This study was supported by Chang Gung Medical Research Foundation to CCS (CMRPG2D0371, CMRPG2D0372, CMRPG2D0373, CLRPG2G0081, CLRPG2G0082 and CLRPG2G0083).

Competing interests None declared.

Patient consent for publication Not required.

Ethics approval The current study was approved by both the National Health Insurance Administration and the Institutional Review Board of Chang Gung Memorial Hospital, Taiwan.

Provenance and peer review Not commissioned; externally peer reviewed.

Data availability statement Data are available upon reasonable request. The data used in the current study are available upon reasonable request.

Open access This is an open access article distributed in accordance with the Creative Commons Attribution Non Commercial (CC BY-NC 4.0) license, which permits others to distribute, remix, adapt, build upon this work non-commercially, and license their derivative works on different terms, provided the original work is properly cited, appropriate credit is given, any changes made indicated, and the use is non-commercial. See: http://creativecommons.org/licenses/by-nc/4.0/.

ORCID iD

Chi Chin Sun http://orcid.org/0000-0001-9466-6986

\section{REFERENCES}

1 Wilde C, Poostchi A, Mehta RL, et al. Prevalence of age-related macular degeneration in an elderly UK Caucasian population-The Bridlington eye assessment project: a cross-sectional study. Eye 2017;31:1042-50.

2 Attebo K, Mitchell P, Smith W. Visual acuity and the causes of visual loss in Australia. the blue Mountains eye study. Ophthalmology 1996;103:357-64.

3 Klein BE, Klein R, Sponsel WE, et al. Prevalence of glaucoma. The Beaver dam eye study. Ophthalmology 1992;99:1499-504.

4 Klein BE, Klein R, Linton KL. Prevalence of age-related lens opacities in a population. The Beaver dam eye study. Ophthalmology 1992;99:546-52.

5 Tielsch JM, Sommer A, Witt K, et al. Blindness and visual impairment in an American urban population. The Baltimore eye survey. Arch Ophthalmol 1990;108:286-90.

6 Smith W, Assink J, Klein R, et al. Risk factors for age-related macular degeneration: pooled findings from three continents. Ophthalmology 2001;108:697-704

7 Klein R, Lee KE, Gangnon RE, et al. Incidence of visual impairment over a 20-year period: the Beaver dam eye study. Ophthalmology 2013;120:1210-9.

8 Hong T, Mitchell P, Rochtchina E, et al. Long-term changes in visual acuity in an older population over a 15-year period: the blue Mountains eye study. Ophthalmology 2013;120:2091-9. 
9 Tsai D-C, Chen S-J, Huang C-C, et al. Age-related macular degeneration and risk of degenerative dementia among the elderly in Taiwan: a population-based cohort study. Ophthalmology 2015;122:2327-35.

10 Christoforidis JB, Tecce N, Dell'Omo R, et al. Age related macular degeneration and visual disability. Curr Drug Targets 2011;12:221-33.

11 van Landingham SW, Massof RW, Chan E, et al. Fear of falling in age-related macular degeneration. BMC Ophthalmol 2014;14:10.

12 Varadaraj V, Mihailovic A, Ehrenkranz R, et al. Gait characteristics of age-related macular degeneration patients. Trans/ Vis Sci Technol 2017;6:14.

13 Chung S-D, Hu C-C, Lin $\mathrm{H}-\mathrm{C}$, et al. Increased fall risk in patients with neovascular age-related macular degeneration: a three-year followup study. Acta Ophthalmol 2017;95:e800-1.

14 Sözen T, Özıșık L, Bașaran Nursel Çalık, Basaran NC. An overview and management of osteoporosis. Eur J Rheumatol 2017;4:46-56.

15 Yang N-P, Deng C-Y, Chou Y-J, et al. Estimated prevalence of osteoporosis from a nationwide health insurance database in Taiwan. Health Policy 2006;75:329-37.

16 Curtis EM, Moon RJ, Harvey NC, et al. The impact of fragility fracture and approaches to osteoporosis risk assessment worldwide. Bone 2017;104:29-38.

17 Cummings SR, Melton LJ. Epidemiology and outcomes of osteoporotic fractures. Lancet 2002;359:1761-7.

18 Groff H, Kheir MM, George J, et al. Causes of in-hospital mortality after hip fractures in the elderly. Hip Int 2020;30:204-209.

19 Meunier A, Maczynski A, Asgassou S, et al. Mortality and functional independence one year after hip fracture surgery: extracapsular fracture versus intracapsular fracture. Geriatr Psychol Neuropsychiatr Vieil 2019;17:153-62.

20 Dargent-Molina P, Favier F, Grandjean H, et al. Fall-related factors and risk of hip fracture: the EPIDOS prospective study. Lancet 1996;348:145-9.

21 Cummings SR, Nevitt MC, Browner WS, et al. Risk factors for hip fracture in white women. study of osteoporotic fractures Research Group. N Engl J Med 1995;332:767-73.
22 Loriaut $\mathrm{P}$, Loriaut $\mathrm{P}$, Boyer $\mathrm{P}$, et al. Visual impairment and hip fractures: a case-control study in elderly patients. Ophthalmic Res 2014;52:212-6.

23 Ivers RQ, Cumming RG, Mitchell P, et al. Visual risk factors for hip fracture in older people. J Am Geriatr Soc 2003;51:356-63.

24 Cox A, Blaikie A, MacEwen CJ, et al. Visual impairment in elderly patients with hip fracture: causes and associations. Eye 2005;19:652-6.

25 Kwan MM-S, Close JCT, Wong AKW, et al. Falls incidence, risk factors, and consequences in Chinese older people: a systematic review. J Am Geriatr Soc 2011;59:536-43.

26 Wolinsky FD, Fitzgerald JF, Stump TE. The effect of hip fracture on mortality, hospitalization, and functional status: a prospective study. Am J Public Health 1997;87:398-403.

27 Almeida LRS, Valenca GT, Negreiros NN, et al. Predictors of recurrent falls in people with parkinson's disease and proposal for a predictive tool. J Parkinsons Dis 2017;7:313-24.

$28 \mathrm{Pi} \mathrm{H-Y,} \mathrm{Gao} \mathrm{Y,} \mathrm{Wang} \mathrm{J,} \mathrm{et} \mathrm{al.} \mathrm{Risk} \mathrm{factors} \mathrm{for} \mathrm{in-hospital}$ complications of fall-related fractures among older Chinese: a retrospective study. Biomed Res Int 2016;2016:8612143.

29 Hsu W-M, Cheng C-Y, Liu J-H, et al. Prevalence and causes of visua impairment in an elderly Chinese population in Taiwan: the Shihpai eye study. Ophthalmology 2004;111:62-9.

30 Anastasopoulos E, Yu F, Coleman AL. Age-related macular degeneration is associated with an increased risk of hip fractures in the Medicare database. Am J Ophthalmol 2006;142:1081-3.

31 Ensrud KE, Schousboe JT. Clinical practice. vertebral fractures. $N$ Engl J Med 2011;364:1634-42.

32 Leucht P, Fischer K, Muhr G, et al. Epidemiology of traumatic spine fractures. Injury 2009;40:166-72.

33 McCarthy J, Davis A. Diagnosis and management of vertebral compression fractures. Am Fam Physician 2016;94:44-50.

34 Ekholm R, Adami J, Tidermark J, et al. Fractures of the shaft of the humerus. An epidemiological study of 401 fractures. J Bone Joint Surg Br 2006;88:1469-73.

35 Bahrs C, Stojicevic T, Tanja S, Blumenstock G, et al. Trends in epidemiology and patho-anatomical pattern of proximal humeral fractures. Int Orthop 2014;38:1697-704. 